\title{
Attrition and Conviction Rates of Sexual Offences in Europe: Definitions and Criminal Justice Responses
}

\author{
Jörg-Martin Jehle
}

Published online: 14 January 2012

(C) Springer Science+Business Media B.V. 2012

\begin{abstract}
The "loss" of cases within the criminal justice chain, especially from police to conviction level is known as attrition - a phenomenon that can be observed in every criminal justice system and for every offence type. But is this attrition particularly strong for sexual offences as theories based on the so-called "rape myths" suppose? This question is dealt with by this paper; it studies the different conviction ratios of sexual offences in Europe and tries to evaluate the resulting findings. The data presented are based upon the work done by the expert group for the European Sourcebook (ESB) of Crime and Criminal Justice Statistics and a special EU-funded project on "Defining and Registering Criminal Offences and Measures, Standards for a European Comparison". In order to gain a basis for comparison, the differences between the national legal concepts and definitions are discussed. Then attrition and conviction rates (understood as the ratio of suspected to convicted persons) are examined, firstly for different crime types in order to show the relative importance of attrition in the field of sexual offences, secondly with a special focus on rape, sexual assault and sexual abuse of minors in some European countries. Beyond these mere statistical data the question whether there are particular reasons for the selection process in cases of sexual offences is raised.
\end{abstract}

Keywords Attrition - Conviction rate - Criminal justice statistics - European sourcebook . International comparison $\cdot$ Sexual offences

\section{Introduction}

Prosecution of sexual violence has long been a focal matter of discussion for the general public and the academic world; be it the exact definition of a sexual crime or the way

A shorter version of this paper was presented at the 10th Annual Meeting of the European Society of Criminology (Liège, 8-11 September 2010).

J.-M. Jehle $(\bowtie)$

Institute of Criminal Law and Justice, University of Göttingen, Platz der Göttinger Sieben 6, D-37073

Goettingen, Germany

e-mail: jjehle@jura.uni-goettingen.de 
victims and offenders are treated within the criminal justice system. Especially the rate of attrition between police and court level has often been criticized based upon the assumption that this attrition has something to do with a special social perception of rape and similar crimes. Accordingly, so-called "rape myths" may influence the persons concerned as well as the law enforcement agencies and may lead to prejudices that blame the victim and relieve the perpetrator (Brown et al. 2007; Temkin and Krahe 2008; Gerger et al. 2007; Ben-David and Schneider 2005; Anderson et al. 1997; Burt 1980). Therefore they can also - if taken seriously - have influence on the way cases of sexual aggression are handled after they have happened.

If these rape myth theories were valid one should find special attrition rates for rape and sexual assault everywhere. Therefore the starting point is the question if the attrition rate of sexual offences is particularly high and if this rate is similar within Europe. Examining this one has to study the following questions:

What is the meaning of attrition and how can it be measured by given statistical data?

In which (different) ways do national criminal justice systems define and record special types of sexual offences?

What are the findings about rates of sexual offences, suspects, convicted and sentenced persons and to what extent attrition processes take place within the criminal justice chain in certain European countries?

Can case tracking studies give explanations for such attrition processes?

\section{Source of Information and Data Base}

A study of the selection process within the criminal justice chain should ideally follow the cases from the report to the police to the stage of prosecution and further to court level. Since during the procedural course various processes of modifying charges and of combining or separating proceedings can occur, studies are usually designed as file analysis for a restricted number of proceedings - either prospectively or retrospectively (see the example below, VII.). But of course these studies cannot be generalized. A representative picture could be gained if real flow statistics existed which allow one to follow criminal cases from the very beginning to the end of proceedings. This would imply that all data recording institutions in a national criminal justice system use the same categories, apply the same statistical rules and input data in compatible data bank systems. Unfortunately no European country could present such a flow of statistics even though there are some approaches towards this goal, for example in the Netherlands and in Sweden.

Therefore one has to stick to conventional statistics which means that one cannot observe the real flow of cases but only compare quantities on the different levels and thus estimate the loss from level to level. For this purpose the European Sourcebook of Crime and Criminal Justice Statistics provides the data needed. The Sourcebook started under the umbrella of the Council of Europe. A group of specialists presented quantitative data on crime and criminal justice systems collected from 36 European countries covering the period 1990 to 1996. It included both statistical data and information on the statistical rules and the definitions behind these figures. But instead of going along with the approach of periodic surveys carried out by the $\mathrm{UN}^{1}$ and INTERPOL, ${ }^{2}$ which rely on the provision of

\footnotetext{
${ }^{1}$ United Nations Survey on Crime Trends and the Operations of Criminal Justice Systems (CTS); www.unodc.org.

${ }^{2}$ INTERPOL International Crime Statistics (now discontinued).
} 
data by national sources asked to follow standard definitions, the group adopted a new methodology, as they felt that their approach would allow more comprehensive and accurate data to be produced. A coordinated network of national correspondents - who have full responsibility for the accuracy of the data provided by their respective countries provides data from current statistical sources within each country. These data are then supplemented by the collection of information on statistical and legal definitions.

The first edition (Council of Europe 1999) was followed by the second (Aebi et al. 2003), third (Aebi et al. 2006) and recently (2010) the fourth edition covering the years 2003 - 2007 (Aebi et al. 2010). The latter has been made possible with support from the European Commission under the AGIS program. ${ }^{3}$ While the results presented in the ESB are not the direct project results (for these, cf. Jehle and Harrendorf 2010), the data collection instrument developed in the course of AGIS project was also used for this fourth edition. Especially the scope of recorded offences could be broadened, standard definitions of new offences could be developed and the national deviations from these concepts could be determined. In the field of sexual offences the already existing data on rape were complemented by data on sexual assault and sexual abuse.

The basic structure of five chapters - offences and offenders known to the police, prosecution, convictions and sentences, corrections and survey data - has been maintained throughout all four editions. However, only for the police and the conviction level detailed offence-related data are available. In consequence the attrition process in the form of an offence related loss of cases can only be observed by comparing the quantities of offences/ respective offenders on police level with convictions/respective convicted persons on court level (see below). What is happening in between takes place in a sort of statistical black box.

\section{Definitions of Sexual Offences and their Comparability}

One of the biggest problems in the area of comparative criminology, if it refers to official crime data, is the incompatibility of national offence definitions. To overcome this problem at least partly the European Sourcebook adopted the following procedure: For all offences included, a standard definition was used and countries were invited to follow the standard definition as closely as possible. Offence definitions and corresponding comments are given in the appendix of the ESB, providing a standard definition for each of the selected offences and a list of those countries that were not able to entirely meet this definition (with an indication of which elements of the definition they were unable to meet either due to statistical or legal reasons).

The following tables show the standard definitions used for sexual offences included in the 4th edition of the European Sourcebook - rape, sexual assault and sexual abuse of minors - and which countries had to (at least partly) deviate from this definition. Exemplarily the focus will be on France, Germany, the Netherlands, Poland, Sweden and for the UK on England \& Wales:

France is exemplary for Romanic legal cultures and has an explicitly inquisitorial legal system.

Germany has a legal culture known for a traditional binding to the principle of legality and of mandatory prosecution which has, however, allowed increasing breaches of these

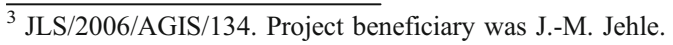


during the past decades so that the legislative ideal type is now the exception. It also has the largest national population in Europe and representative statistics.

The Netherlands provides an excellent example of a smaller western European country, has very good statistics and is one of the most advanced countries in terms of dealing with cases informally (without a court hearing).

Poland provides an example of the eastern European culture, with a tradition of binding its prosecution services strictly to the principle of legality and a far-reaching decriminalization of less serious offences.

Sweden is included as a representative of the Scandinavian legal culture which differs from the rest of Europe, in particular in relation to the role of the police. It also uses very broad definitions for sexual crimes such as rape.

England \& Wales provides an insight into a common law system which has only relatively recently introduced a prosecution service and which itself is fairly stringently required to bring a large number of cases to court. Within that system the police, however, have broad discretion to deal with cases themselves, meaning a lower input to the prosecutorial level than in other countries.

Detailed data for the other countries can be found in Aebi et al. (2010).

\section{Rape}

The standard definition for rape was slightly modified after the first edition of the questionnaire, and then remained identical in the 2nd and 3rd editions of the European Sourcebook. For the 4th edition the definition was updated after being evaluated and optimized by the AGIS project. It is specified as "sexual intercourse with a person against her/his will" and backed up with a list of items to include in and to exclude from the data.

Overall half of the countries could meet the ESB standard definition of rape at police level; 19 countries followed the standard definition of rape proposed by the questionnaire.

For the other countries, some items could not be included in or excluded from the data. Mainly, some countries could not include sexual intercourse without force with a helpless person in their rape data, and others had to exclude penetration other than vaginal. Only three countries excluded violent intra-marital sexual intercourse, but four countries could not include sexual intercourse with force with a minor in their data. Also some had to include sexual assault in their data.

Most countries could meet the ESB standard definition of rape at conviction level; there are fewer deviations from standard definitions for conviction statistics than for police statistics.

The following table shows the exact offence definition for rape used in the 4th edition of the European Sourcebook (Table 1). The countries in focus could closely follow the standard definition of rape; but only Germany has no deviations at all. France and Sweden have similar definitions, but cannot exclude sexual intercourse with a minor without force from their rape data, neither on police nor on conviction level. This means there is an overlapping definitional area of "rape" on the one side and sexual abuse of minors (see below) on the other.

The Netherlands and England \& Wales do not include sexual intercourse without force with a helpless person in their data on rape (police and conviction statistics) and Poland was not able to exclude other forms of sexual assault from their data. Evidently the Polish criminal justice system does not differentiate between rape and sexual assault; therefore it also cannot provide any data for sexual assault (see below). 
Table 1 ESB-definition of rape for countries in the focus group (data only for England \& Wales, France, Germany, the Netherlands, Poland and Sweden)

Rape: sexual intercourse with a person against her/his will (per vaginam or other)

Deviations:

\begin{tabular}{lll}
\hline $\begin{array}{l}\text { Include the following: } \\
\text { penetration other than vaginal (e.g. buggery) }\end{array}$ & police statistics & conviction statistics \\
$\begin{array}{l}\text { violent intra-marital sexual intercourse } \\
\text { sexual intercourse without force with a helpless person } \\
\text { sexual intercourse with force with a minor }\end{array}$ & NL, England \& Wales & NL, England \& Wales \\
$\begin{array}{ll}\text { attempts } \\
\begin{array}{l}\text { Exclude the following: } \\
\text { sexual intercourse with a minor without force }\end{array}\end{array}$ & F, SW \\
\begin{tabular}{l} 
other forms of sexual assault \\
\hline
\end{tabular}
\end{tabular}

\section{Sexual Assault}

Sexual assault was added to the European Sourcebook as an offence category in its 4th edition and is defined as "physical sexual contact with a person against her/his will".

A difficulty here is that the distinction between sexual assault with violence and acts committed without violence and/or sexual abuse of minors and/or rape is not always evident. This might also be the reason why 18 countries did not report any data on sexual assault at all and why some countries, based on a wider concept of sexual molestation, were not able to exclude verbal or any other form of nonphysical molestation from their data.

All but one reporting countries included all sexually motivated physical contacts with violence $^{4}$ in their data; attempts are also included nearly everywhere. Six countries could not include sexually motivated acts committed with abuse of authority or undue pressure and sexually motivated acts committed against a marital partner against her/his will and seven countries could not include sexually motivated acts committed against a helpless person in their data.

Most deviations occurred with acts committed without violence and acts committed against persons under the age of consent: 12 and 11 countries respectively could not exclude those options from their data on sexual assault in their police and/or conviction statistics.

The following table shows the exact definition for sexual assault with its particular categories (Table 2). For the countries in focus there are a lot more deviations from the standard definition for sexual assault than there are for rape. Again only Germany can completely follow the standard definition. For Poland there is no data available for sexual assault, as they cannot separate this offence from their rape data.

Sweden shows the most deviations and cannot exclude any of the non-physical forms of sexual assault from their data. France and the Netherlands use definitions similar to the one of the European Sourcebook, but also cannot exclude non-physical acts. Apparently theses countries follow a broader legal concept of sexual delinquency - with consequences for the statistical data (see below).

\footnotetext{
${ }^{4}$ Except those considered rape.
} 
Table 2 ESB-Definition of sexual assault for countries in the focus group (data only for England \& Wales, France, Germany, the Netherlands, Poland and Sweden)

Sexual assault: physical sexual contact with a person against her/his will

Deviations:

Include the following:

police statistics

conviction statistics

any sexually motivated physical contacts committed with violence

any sexually motivated acts committed with abuse of authority or England \& Wales England \& Wales undue pressure

any sexually motivated acts committed against a helpless person

England \& Wales England \& Wales

any sexually motivated acts committed against a marital partner

against her/his will

attempts

Exclude the following:

any verbal or any other form of non-physical molestation

SW F, SW

pornography

SW SW

acts committed without violence

NL, SW, England NL, SW, England

\& Wales \& Wales

acts committed against persons under the age of consent

(considered as abuse of minors)

F, SW, England SW, England

\& Wales \& Wales

acts considered as rape (see above)

SW SW

England \& Wales are not able to include sexually motivated acts committed with abuse of authority or undue pressure or sexually motivated acts committed against a helpless person on the one hand, on the other hand they are not able to exclude acts committed without violence and acts committed against persons under the age of consent in their data on sexual assault in both their police and their conviction statistics.

\section{Sexual Abuse of Minors}

Sexual abuse of minors was also added to the European Sourcebook as an offence category in its 4th edition and is defined as "sexual intercourse, or any other form of physical sexual contact, with a person below the age of consent".

The age of consent, i.e. the age under which a minor cannot validly consent to having sexual contacts, differs for the responding countries between 14 and 18 years of age. For the majority, 20 countries, the age of consent is 14 or 15 years.

All countries were able to include sexual intercourse or any other form of physical sexual contact committed without violence with a minor below the age of consent and acts committed by persons above the age of consent in their data.

Acts committed by a person below the age of consent could not be included everywhere, especially in conviction statistics, probably because in many countries the age of consent is not higher than the age of criminal responsibility. They were excluded in six countries from their police statistics and in 14 countries from their conviction statistics.

Attempts are only excluded in three countries and verbal or any other form of nonphysical molestation of persons under the age of consent is not excluded in seven countries. Child pornography is only included in two countries and acts considered as rape are included in five countries. 
The following table shows the exact definition for sexual abuse of minors with its particular categories (Table 3). For the countries in focus there are few deviations from the standard definition of sexual abuse of minors of the European Sourcebook.

The Netherlands and England \& Wales were able to completely meet the standard definition with their data; France, Germany and Sweden use similar definitions, but still had to deviate. They all had to exclude acts committed by a person below the age of consent from their data Germany both on police and conviction level, France and Sweden in their conviction statistics.

Poland cannot exclude verbal or any other form of non-physical molestation and acts considered as rape in their data on both police and conviction levels.

\section{The Concept of Attrition and Conviction Ratios and the Statistical Limits}

The phenomenon of attrition, the loss of cases from the level of police to the level of conviction, is a well-known general fact in the criminal justice system. It is not specific for sexual offences, but there are hints that for a number of reasons the selection process might be stronger here than elsewhere.

In general, within the criminal justice chain one finds various decriminalization and depenalization options and possibilities of discretion at police and prosecution service level differing from country to country.

The prosecution as the intermediate stage between police and court level plays a decisive role for the attrition process in most European countries (Jehle et al. 2008). But in any case the prosecution service's workload depends on the input from the police level. If a large proportion of cases are decriminalized, subject to a final drop of cases by the police, the prosecution service will concentrate on more serious offences and thus requires less discretionary powers. If - on the other hand - the police are obliged to hand all offences over to the prosecution service, the criminal justice system will have to allow considerable discretion at prosecution level.

Unfortunately, in consequence of the lacking data of national statistics, the European Sourcebook cannot provide any detailed offence related data on prosecution level (see

Table 3 ESB-Definition of sexual abuse of minors for countries in the focus group (data only for England \& Wales, France, Germany, the Netherlands, Poland and Sweden)

Sexual abuse of minor: sexual intercourse, or any other form of physical sexual contact, with a person below the age of consent

Deviations:

\begin{tabular}{|c|c|c|}
\hline $\begin{array}{l}\text { Include the following: } \\
\text { sexual intercourse or any other form of physical sexual } \\
\text { contact committed without violence }\end{array}$ & police statistics & conviction statistics \\
\hline $\begin{array}{l}\text { acts committed by a person below the age of consent } \\
\text { acts committed by persons above the age of consent } \\
\text { attempts }\end{array}$ & $\mathrm{D}$ & $\mathrm{F}, \mathrm{D}, \mathrm{SW}$ \\
\hline $\begin{array}{l}\text { Exclude the following: } \\
\text { verbal or any other form of non-physical molestation } \\
\text { child pornography }\end{array}$ & PL & PL \\
\hline acts considered as rape & PL & PL \\
\hline
\end{tabular}


above II.). Therefore important processes of selection cannot be observed: There are a lot of reasons why the public prosecutor does not bring a case to the court. Besides the presumably most frequent dismissal because of lack of evidence (see below VII.), sexual offences may "vanish" by redefinition. Whereas the police have defined the criminal act as a rape, the offence may be downgraded by the public prosecutor or later by the court to a sexual assault or an attempted rape to a mere bodily injury.

The statistical data available here refer to four different levels: police, prosecution, courts and prisons. What happens on the respective level is registered separately and recorded independently of how the case has been handled on a former level. Every level usually follows its own rules and even crucial items might be recorded differently, especially statistical counting units as the offence or the proceedings. Furthermore there are often different dates for the recording of data - a reason why suspects recorded in police statistics in one year are not necessarily identical with the convicted persons in the same year. Nonetheless, as a first quantitative approach, it is fruitful and legitimate to use these figures to compare the quantities of cases on the different levels and in such a way estimate the loss from level to level. Of course, these decreases are not self evident, but need to be interpreted thoroughly taking into account all the statistical and definitional restrictions mentioned above.

However, there is a further limitation: Detailed, offence-related information is only available on police and court level. Therefore we can only compare the offences and suspected persons on police level on the one hand and the convicted and sentenced persons on court level on the other. Thus the quantitative amount of reduction from police to court level can be shown, but not the reasons for it in terms of the decisive disposals made by the public prosecutor.

If one wants to measure the attrition between police and court levels one should refer to the same statistical unit, namely persons. Hence we relate the number of suspected persons to the number of convicted persons and take the ratio as a measure of attrition (this socalled conviction ratio should not be mixed up with conviction rates used in the ESB as convicted persons per 100,000 population).

To sum up, our approach is a first incomplete step towards a quantitative description of the selection and attrition processes going on within the criminal justice chain in the field of sexual offences. For future improvements, further representative, in-depth studies should be undertaken or even better flow statistics (see above II.) should be established. Only these could give exact answers to simple, but essential questions like the following:

How many cases/victims were reported, how many suspects were recorded? Of these: How many proceedings were opened/closed? Of these: How many suspects were charged/ indicted? Of these: How many persons were convicted/acquitted? Of these: How many persons were sentenced to a fine, a prison sentence? Of these: How many prisoners were released early etc?

If complete answers to these questions could be given one could easily measure the efficiency and the effectiveness of criminal investigation, prosecution, proceedings and sanctioning as a whole or in specific fields like sexual offences.

Lovett and Kelly (2009) used a somewhat similar approach in their case-tracking study. In the first part of the study a collection on national level on reporting, prosecution and conviction data for rape for 33 European countries for the years 2001-2007 was made and analyzed for similarities and differences in attrition and conviction rates in Europe. The following conclusions were drawn: there are substantial variations in reporting rates per 100,000 of the population, there is a correlation between high conviction rates and low reporting and the majority of the European countries, especially of the last decade, exhibit 
the classic attrition pattern - increased reporting over a sustained period accompanied by a falling conviction rate.

In the second part of the study, a quantitative content analysis of 100 case files in eleven European countries was done to analyze the similarities and differences in attrition processes and conviction rates with varying judicial systems and socio-legal cultures (see also VII.). This case study was supplemented by interviews with key informants, the mapping of the relevant legal process and procedures and the creation of time line documentation of social and legal responses to sexual violence in the respective countries.

Inter alia they came to the conclusion that low conviction rates are not just a function of reporting rates and that the extensiveness of the legal definition of the crime of rape is not an explanatory variable for low conviction rates either. They also found that all the adversarial systems have low conviction rates and that consent and force based legal definitions are increasingly similar.

The main differences between the study by Lovett and Kelly (2009) and the approach of this paper are that the data used here is based on the same definition - the standard definition of the European Sourcebook -, that rape is not considered isolated, but in connection with other violent and nonviolent forms of sexual offences and that the conviction ratio is calculated by using the same statistical unit, i.e. persons, relating the number of convicted persons to the number of recorded suspects instead of reported offences.

\section{Offence-related Comparisons of Attrition and Conviction Rates}

Before focusing on sexual offences one should examine the general process of attrition between police and court level by comparing different offence groups in order to find out whether there are certain peculiarities for sexual offences. Of course, this could be done for every country included in the European Sourcebook. But here we take just Germany as an example: the following graph shows the rates of crime, suspected offenders, convicted persons and prison sentences per 100,000 inhabitants for exemplary offences in the year 2008 (Fig. 1). As a measure for attrition the conviction ratios calculated in relation to suspected and convicted persons for each offence are additionally given.

The highest conviction ratio is found for the offence of sexual abuse $-30 \%$ - and for robbery with $29 \%$; the lowest for sexual assault with $16 \%$. The conviction ratios for rape and sexual assault are remarkably low, but not exceptionally so. They are on the same level as assault (17\%, not shown here) and not much lower than those for homicide.

Even though the conviction ratios appear to be similar, the reasons behind these selection processes between police and court level might differ: For example, concerning homicides it seems plausible to assume that one of the major reasons for the attrition is the fact that offences originally defined as (attempted) homicides by the police are downgraded to assault, assault leading to death or negligent killing by the court because the intent of the perpetrator to kill could not be proofed. On the other hand the attrition in the fields of sexual offences might mainly be a consequence of lacking or deficient evidence (see below).

\section{Country-related Comparisons of Attrition and Conviction Rates of Sexual Offences}

Attrition is a general phenomenon to be found in every criminal justice system. But the amount of attrition could differ from country to country depending on the different input into the system and the different legal cultures. 


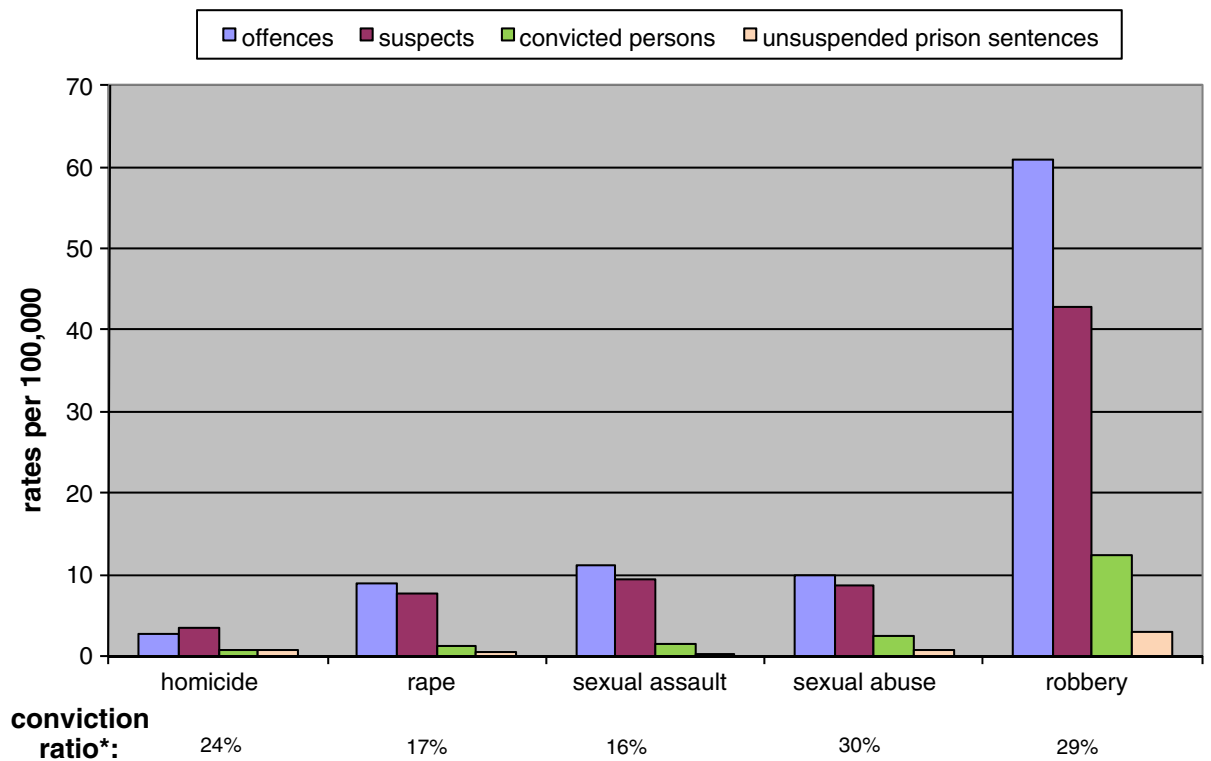

${ }^{*}$ Convicted persons per suspects in \%.

Fig. 1 Rates of crime, suspects, convicted persons, prison sentences in Germany in 2008

The following three graphs show the number of offences, suspected offenders, convicted persons and unsuspended prison sentences in rates per 100,000 inhabitants for a few selected countries in 2006: France, Germany, the Netherlands, Poland, Sweden and England $\&$ Wales. Again the ratio of convicted persons to suspects in per cent, the so-called conviction ratio, is shown. (Fig. 2)

For rape one can observe a wide range of attrition between the individual countries. Poland has the highest conviction ratio by far, namely $71 \%$; whereas the lowest conviction ratio for $2006-15 \%$ - is found for Germany (for details see below, VII.).

Sweden is clearly outstanding; it reports the highest number of rape cases: 46 per 100,000 population. This number is influenced by the new Swedish legislation on sexual crimes, which came into force on April 1st 2005 and had the purpose "to further strengthen and make clear the absolute right of every individual to personal and sexual integrity and sexual self-determination and to highlight and strengthen in different ways protection for children and young people from sexual violations" . The concept of "sexual relations" (sexuellt umgänge) was replaced with the concept of "sexual act" (sexuell handling), which is somewhat broader and more neutral in its meaning than "sexual relations".

This broadening of the concept for sexual offences included an expansion of the legal definition for the crime of rape. The requirement of force was lowered and it is now sufficient "if the offender has forced the victim to engage in a sexual act through assault, violence or the threat of a criminal act". For the requirement of violence, less grievous forms are sufficient and for threat, it is no longer required that the "threat be of the kind that

\footnotetext{
${ }^{5}$ Details: Government Offices of Sweden, "New legislation on sexual crimes": http://www.sweden.gov.se/sb/ d/574/a/46797.
} 


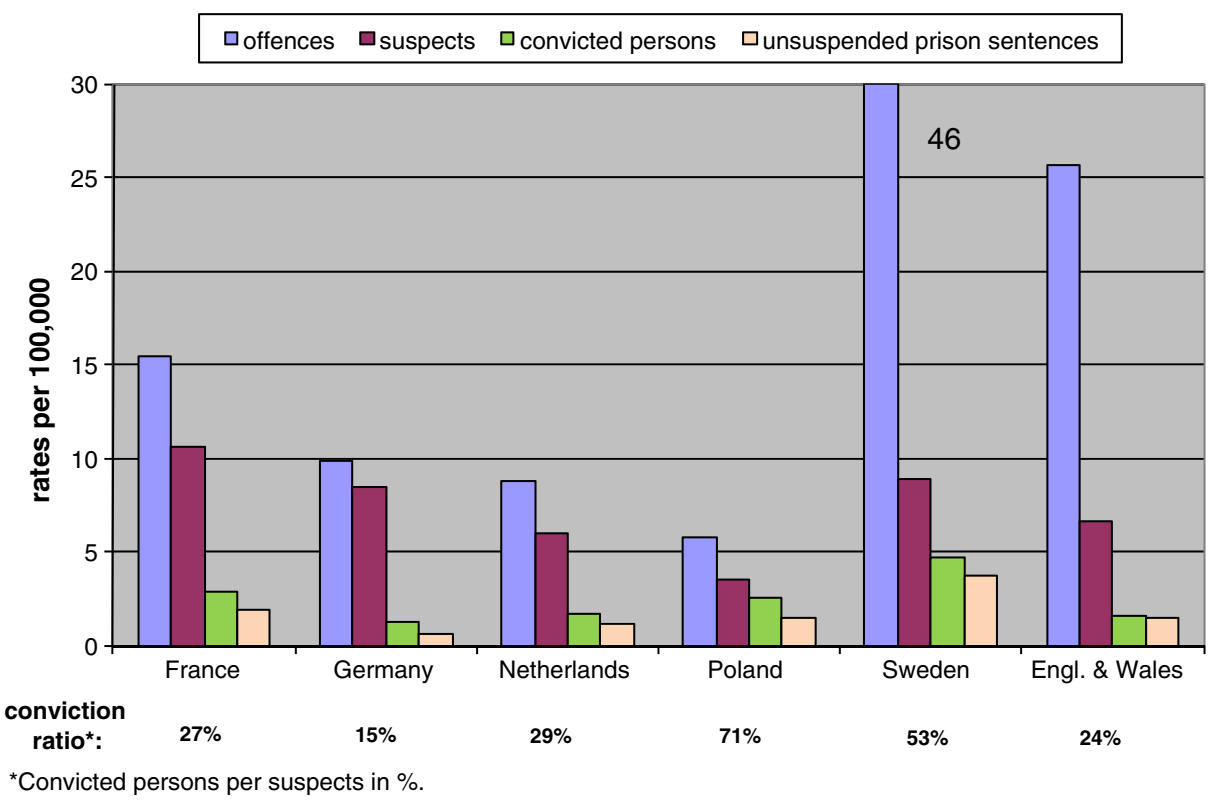

Fig. 2 Rape in European countries in 2006

constitutes a threat of imminent violence endangering life or health or some other more significant interest". Also cases of "sexual exploitation" are now included in the crime of rape and a new penal provision on rape of a child was introduced.

In addition there is a new offence called "sexual exploitation of a child", which regulates cases of rape of a child that are less serious in view of the circumstances of the crime.

In the years 2003 and 2004 the rate of rape per 100,000 in Sweden was at 29, in 2005 at 42 , in 2006 at 46 and at 53 in 2007. This is an increase of $84 \%$ between the years 2003 and 2007 and clearly shows the impact of the new legislation.

A further explanation for the high crime rate is that data for the police statistics in Sweden are collected when the offence is reported to the police (the counting unit is the offence). Multiple offences are counted as two or more offences; an offence committed by more than one person is, as a rule, counted as one offence, but in rape cases as two or more offences. Both of those procedures contribute to the high numbers as well. The fact of higher-than-usual Swedish rape figures has also been visible in earlier ESB editions and was already discussed by (von Hofer 2000).

These extraordinary Swedish figures only relate to reported rape cases. When it comes to suspected persons, the Swedish rates are within the range of other countries like France ${ }^{6}$ and Germany. Only because of the high ratio of $53 \%$ of convicted persons in relation to suspects Sweden has the highest conviction rate of all countries concerned.

In contrast, Poland starts with extremely low rates of rape and of suspected rapists, though the concept of rape is comparatively wide, including all sexual assaults (see above, III). This means that the input in form of reports to the police is comparably low. But on the other side there is an extremely high ratio of convicted persons which leads to a relatively high rate of convicted persons and unsuspended prison sentences per 100,000 inhabitants,

\footnotetext{
${ }^{6}$ In France the definition of rape is also broad and "violence" may be pressure, threat or surprise.
} 
higher than in Germany, the Netherlands and England \& Wales, although the rates of offences and suspects recorded in these countries is quite a bit higher.

Referring to national data, the study by Lovett and Kelly (2009) came to the following results: a conviction ratio of $25 \%$ in France and $13 \%$ in Germany, but in contrast only $6 \%$ in England \& Wales and 10\% in Sweden for rape in 2006. Again here one has to consider, however, that their study - in comparison to the European Sourcebook - did not use a standard definition during data collection and calculated the conviction ratio by relating the number of convictions to the number of reported offences instead of to the number of recorded suspects and the results therefore cannot be directly compared due to the different methods. (Fig. 3).

Sexual assault shows an even wider range of conviction ratios: between $82 \%$ (France) and $14 \%$ (Germany). As Poland could not deliver any data for sexual assault at all ${ }^{7}$ and England \& Wales have no separate count for offenders suspected of a sexual assault, it is not possible to calculate the attrition for those two countries.

The highest rate of sexual assaults counted by the police is found in Sweden again, 84 per 100,000 population. One reason might be that Sweden could not exclude either verbal or any other form of non-physical molestation, pornography, acts committed without violence, acts committed against persons under the age of consent or acts considered as rape from their data as asked by the standard definition. But when it comes to suspects once again the Swedish figures are within the range of other countries like France, Germany and the Netherlands. Then once again the Swedish conviction ratio related to suspects is comparatively high which leads to a high conviction rate per 100,000 population.

France shows a high crime rate and the highest rates of suspects, convicted persons and those sentenced to imprisonment. The unusually high conviction ratio of $82 \%$ is especially striking. One can only guess what the reasons for this could be, in-depth studies are urgently needed regarding this point.

Compared to France, the Netherlands and Sweden, Germany shows the lowest figures by far concerning police recorded offences and suspects as well as convicted persons and those sentenced to a prison sentence. Especially low is the ratio of convicted persons in relation to suspects (Fig. 4). There is no obvious reason for this low ratio or strong attrition respectively, but one has to consider that the conviction ratios are generally low in Germany (see above).

There are no data available for France and England \& Wales on sexual abuse of minors at police level. The Netherlands also cannot report any data at police level, as it is not possible to follow a strict distinction between sexual abuse of minors and sexual assault in their police statistics. ${ }^{8}$

Because of the missing data, it was only possible to calculate attrition for Germany, Poland and Sweden. Between these three countries there is a wide variation of conviction ratios.

The highest figures of sexual abuse of minors counted by the police are again found in Sweden, 28 per 100,000 population. This might be a consequence of their new legislation and its broader concept of sexual crimes. A new provision on "sexual abuse of a child" imposes criminal liability on a person who engages in other sexual acts with a child than

\footnotetext{
${ }^{7}$ It is not possible to separate the data on sexual assault from the data on rape, see above, III.

${ }^{8}$ In Dutch criminal law there is no distinction between 'sexual motivated acts committed against a helpless person' and 'other form of physical sexual contact without violence with a minor'; both are therefore counted under 'sexual assault'.
} 


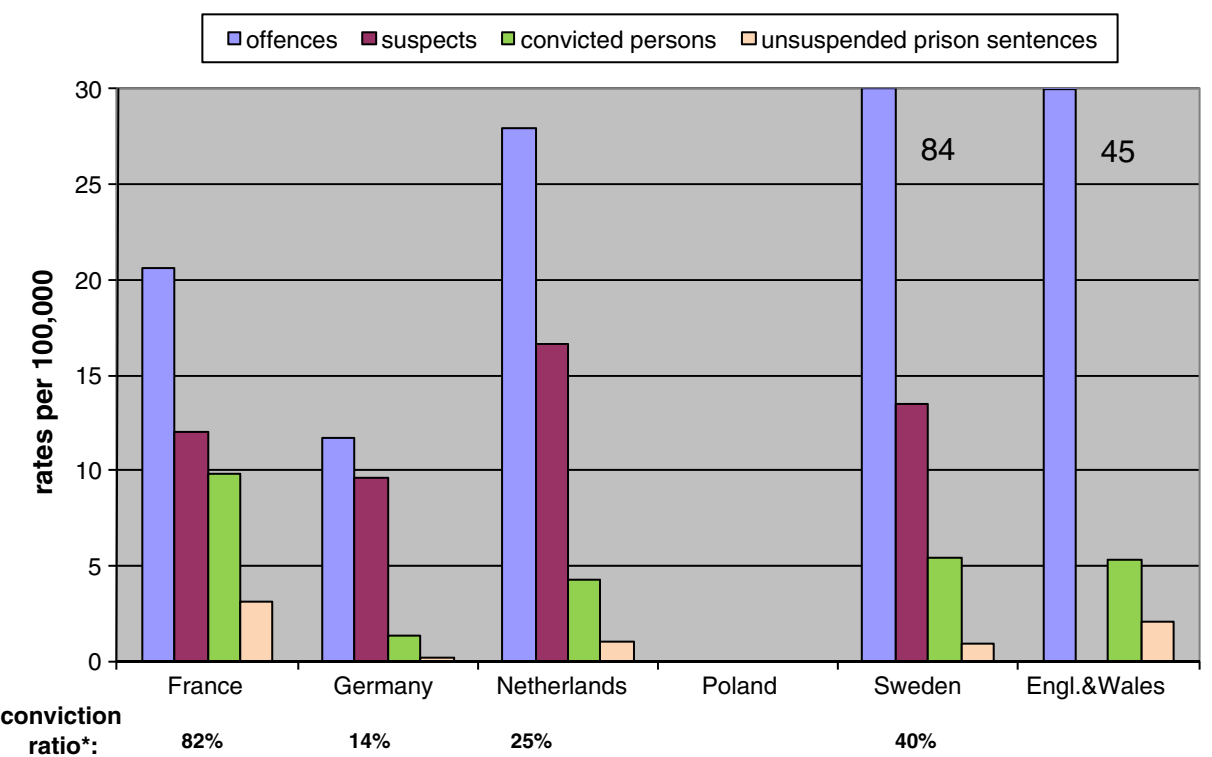

${ }^{\star}$ Convicted persons per suspects in $\%$.

Fig.3 Sexual assault in European countries in 2006

those provided for in the penal provisions on rape of a child and sexual exploitation of a child. Also some of the acts previously defined as sexual molestation (e.g. an offender who induces a victim to masturbate) are now instead defined as sexual coercion or sexual abuse

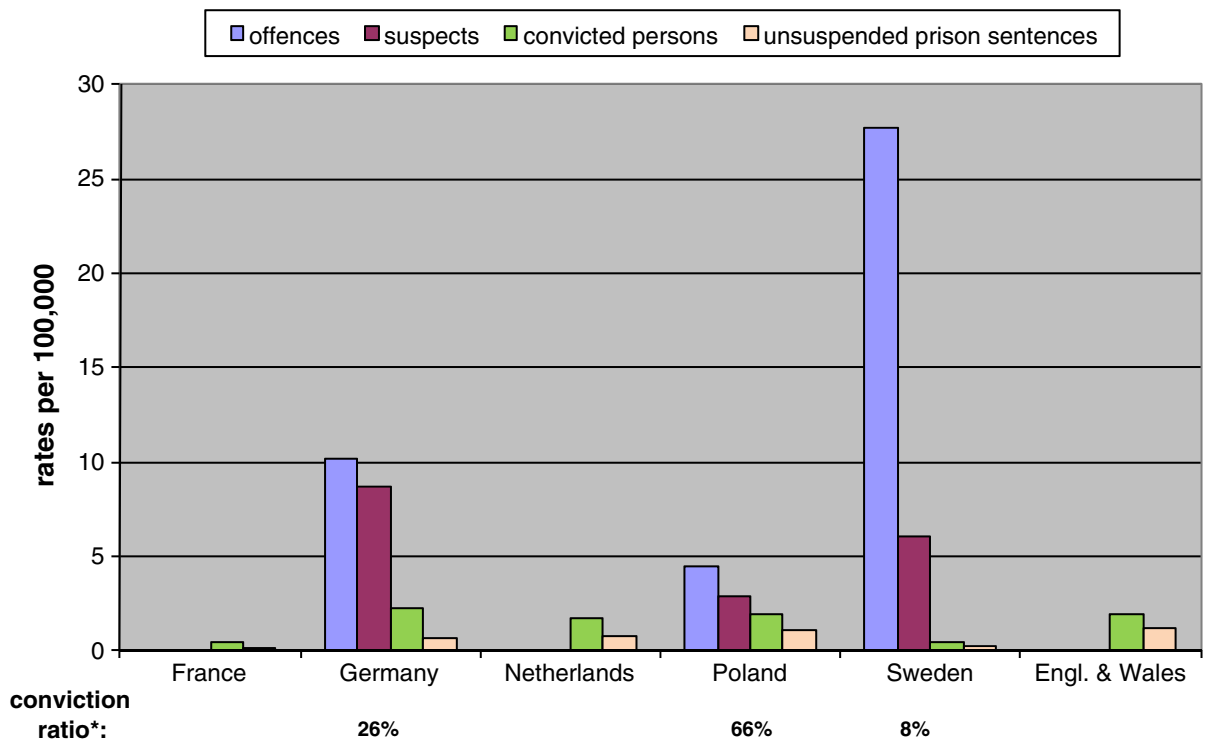

${ }^{\star}$ Convicted persons per suspects in $\%$.

Fig. 4 Sexual abuse of minors in European countries 2006 
of a child. ${ }^{9}$ One may suppose that this expanded criminalization could lead to more suspicion and hence to more reports to the police. However, once again when it comes to offenders recorded by the police the rate lies within the range of the other countries. What is most striking, however, is the extremely low conviction ratio of only $8 \%-$ a phenomenon worthy of further examination.

This also may be due to the new legislation on sexual crimes in Sweden, which leads to more severe (namely intercourse) cases of sexual abuse to be recorded as rapes, even if not in connection with any direct force (see above). Indeed, Swedish conviction statistics show a very strong decrease of convictions for sexual abuse of a minor between 2004 and 2005, only followed by a weaker increase in 2006. One might now hypothesize that judges, compared to the police, apply the new legislation more strictly, redefining abuse cases to rape cases when it comes to convictions.

In contrast - similar to the data on rape - Poland shows the lowest police recorded figures on offences and offenders, yet the highest conviction ratio of $66 \%$ and in consequence a similar number of convicted persons per 100,000 compared to Germany and England \& Wales.

To sum up there are some trends to be observed: On the one hand, the input level in form of reported or recorded offences respectively demonstrates the biggest difference between countries which in a sort of convergent trend shrinks on the subsequent levels. On the other hand, huge differences of attrition in form of conviction ratios related to suspected persons emerge relatively independent of the different input levels. Therefore the statistical data cannot present answers, but provoke a lot of interesting questions to be examined by further in-depth studies.

\section{Special Reasons for the Selection Process in Cases of Sexual Offences}

Whether there are special reasons for the selection process in cases of sexual offences has been a frequent subject of discussion (see above I.).

In order to study this phenomenon, an approach is needed which allows one to trace cases through the criminal justice chain.

The in-depth country casetracking part of the study by Lovett and Kelly (2009) is an outstanding example for such an approach. For this, the first 100 cases consecutively reported rape cases after 1 April 2004 fitting the inclusion criteria - female and adult victims aged over 16, single perpetrator - were collected in the respective countries and their case files analyzed for socio-demographic data on victim and suspect, offence characteristics and contexts of the crime, ${ }^{10}$ the case progress and attrition. For the German data this was done in the city of Stuttgart, which has about 600,000 inhabitants and approximately 100 reported rapes per year. Interestingly, using this data, a conviction ratio of $23 \%$ was calculated for the sample, which is $10 \%$ higher than in the national data set and for which no clear reason was found. They also came to the following conclusions: in Germany the major phase for attrition in rape cases was when the prosecutor had to decide whether to charge the suspect or stop the investigation and, even though the proportion of cases designated false allegation was only three per cent, the reason to discontinue was mainly taken on evidential grounds. Only about $30 \%$ of the cases were referred to court and

\footnotetext{
${ }^{9}$ See above. Also http://www.sweden.gov.se/sb/d/574/a/46797.

${ }^{10}$ See also a German study (Elsner and Steffen 2005), which analyzed case files and police data in Bavaria for information on the phenomenology of sexual crimes, such as the above mentioned categories and in particular with regard to the issue of false allegations,
} 
$23 \%$ resulted in a conviction. The majority of the convicted offenders reflected stereotypes retrieved by the socio-demographic profile, such as having already been subject to the attention of the criminal justice system. In all but one case a custodial sentence was imposed.

As in Germany the conviction ratio is relatively low and the attrition relatively strong in the field of sexual offences, we also want to refer to the results of a German study conducted by the Department of Criminology of Goettingen University (Goedelt 2010). It examined criminal cases of rape and sexual assault (coercion) in two districts of regional courts in Lower Saxony. Since the conviction ratio is almost as low as in Germany as a whole, the results may correspond to general trends. The file analysis started on the level of prosecution, including information on the police activities because the police have no discretion and have to hand over the files to the public prosecutor for further decisions; it ended with the final court decision.

The following diagram demonstrates how the 234 proceedings for rape and sexual assault (coercion) were dealt with on the different levels of the criminal justice chain. (Fig. 5).

The first level shows the four key decisions taken by the prosecutors after having received the file from the police, calculated for a $100 \%$ (234) of the evaluated cases. For the majority (68.8\%), the proceedings were terminated because of lacking or deficient evidence against the suspect, in $3.8 \%$ of the cases the definition originally made by the police was transformed into a charge of a different offence and for only $24.4 \%$ of the accused the charge of rape or sexual assault was actually kept up.

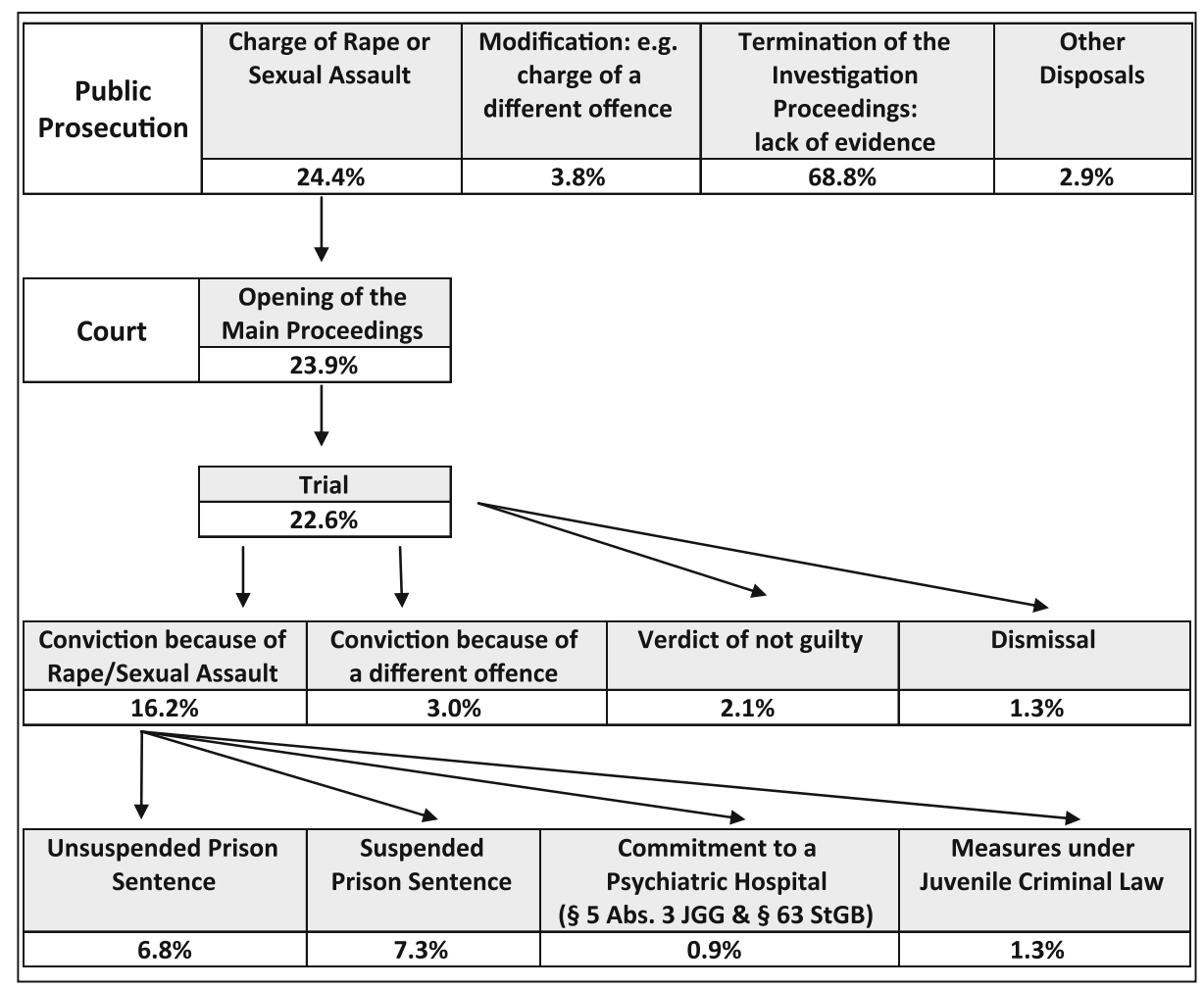

Fig. 5 Course of proceedings for rape and sexual assault in two regional court districts in Germany 2002 
For almost all of those charged, the main proceedings were opened and went to trial. For most of these defendants the main proceedings resulted in a conviction for rape or sexual assault (related to all suspected persons: $16.2 \%$ ) and for a few (3\%) in a conviction because of a different, non-sexual offence. Very few of the proceedings $(1.3 \%)$ were dismissed and very few of the defendants $(2 \%)$ obtained a verdict of not guilty.

Almost all of the persons convicted of rape or sexual assault were sentenced to correctional measures, mostly suspended or unsuspended prison sentences or - rarely - to a commitment to a psychiatric hospital. Only three cases did not end in correctional measures, but in special measures according to the Juvenile criminal law.

Altogether the conviction ratio, meaning the relation of convicted to suspected persons, is $16.2 \%$, which is in line with the German figures for rape (15\%) and sexual assault (14\%), which were $15 \%$ and $14 \%$, respectively, in 2006 (see above, VI.) and $17 \%$ and $16 \%$, respectively, in 2008 (see above, V.).

In both studies the key issue of the attrition process can be clearly identified: the major proportion of cases ended because of lacking or deficient evidence. This ground for terminating proceedings at the prosecution level is not a specific one for sexual offences, however, the underlying reasons for this lack of evidence may be specific: If the victim is the only witness and her testimony is the only evidence, the prosecution depends on the credibility of the victim, if victim and offender are related, the victim can be under pressure to refuse to give evidence, if the sexual intention cannot be proved, the offence could be defined as a simple bodily injury etc.

File analysis can give some hints to such underlying reasons, but cannot determine them. Further research, especially in the form of expert interviews, is needed.

\section{Summary and Implications}

Sexual offences can be regarded as a vague concept in the perspective of an international comparison. Only on national level we can find precise limits for the range of criminal behavior and for the differentiation of special offences.

The differentiation of sexual offences by rape, sexual assault, sexual abuse of minors introduced in the 4th edition of the European Sourcebook is an improvement, though one has to keep in mind that - especially when using the data on sexual assault - the national concepts differ greatly.

Even though there is a core of convergence in European jurisdictions as far as rape and sexual abuse are concerned, one still has to be careful because there are still remarkable deviations in the crime definitions.

Beyond the differences in definitions there are discrepancies in the field of statistical recording on police level and of discretion on prosecution level that influence the figures and conviction ratios. Nevertheless it seems fruitful and legitimate to use the data of the European Sourcebook to examine the question whether the attrition and selection processes in the course of criminal proceedings are especially strong in the field of sexual offences. Because of the lack of flow statistics one cannot follow cases within the criminal justice chain and hence observe the "real" attrition, but only relate quantities on police and court level.

We relate convicted to suspected persons and calculate so-called conviction ratios as a first provisional measure of attrition. When comparing the rates of offences, suspects and convicted persons, as well as the so called conviction ratio between the countries selected (England and Wales, France, Germany, the Netherlands, Poland and Sweden) some trends 
can be observed: On the one hand the input level in form of reported or recorded offences respectively demonstrates the biggest difference which in a sort of convergent trend decreases on the following levels. On the other hand huge differences of attrition in the form of conviction ratios related to suspected persons emerge relatively independently of the different input.

In summary our approach based on data from the European Sourcebook of Crime and Criminal Justice Statistics is a first, incomplete step towards a quantitative description of the selection and attrition processes going on within the criminal justice chain in the field of sexual offences. It cannot present complete answers, but provokes a lot of interesting questions to be examined in further in-depth studies. The current work for the next edition of the European Sourcebook is trying to find better ways for describing and evaluating the attrition processes in terms of total crime and special offences.

\section{References}

Aebi, M. F., et al. (2003). European Sourcebook of Crime and Criminal Justice Statistics (2nd ed.). Den Haag: WODC.

Aebi, M. F., et al. (2006). European Sourcebook of Crime and Criminal Justice Statistics (3rd ed.). Den Haag: WODC.

Aebi, M. F., et al. (2010). European Sourcebook of Crime and Criminal Justice Statistics (4th ed.). Den Haag: WODC.

Anderson, K. B., et al. (1997). Individual Differences and Attitudes Toward Rape: A meta-Analytic Review. Personality and Social psychology Bulletin, 23, 295-315.

Ben-David, S., \& Schneider, O. (2005). Rape Perceptions, Gender Role Attitudes, and Victim-Perpetrator Acquaintance. Sex Roles, 53(5/6), 385-399.

Brown, J. M., et al. (2007). Characteristics associated with rape attrition and the role played by skepticism or legal rationality by investigators and prosecutors. Psychology, Crime \& Law, 13(4), 355-370.

Burt, M. R. (1980). Cultural Myths and Supports for Rape. Journal of Personality and Social Psychology, 38 (2), 217-230.

Council of Europe. (1999). European Sourcebook of Crime and Criminal Justice Statistics. Strasbourg: Council of Europe.

Elsner, E., \& Steffen, W. (2005). Vergewaltigung und sexuelle Nötigung in Bayern. München: KFG.

Gerger, H., et al. (2007). The Acceptance of Modern Myths About Sexual Aggression Scale: Development and Validation in German and English. Aggressive Behavior, 33, 422-440.

Goedelt, K. (2010). Vergewaltigung und sexuelle Nötigung. Untersuchung der Strafverfahrenswirklichkeit. Göttingen: Universitätsverlag.

Jehle, J.-M., \& Harrendorf, S. (2010). Defining and Registering Criminal Offences and Measures. Standards for a European Comparison. Göttingen: Universitätsverlag.

Jehle, J.-M., et al. (2008). The Public Prosecutor as Key-Player: Prosecutorial Case-Ending Decisions. European Journal on Criminal Policy and Research, 14(2-3), 161-179.

Lovett, J., \& Kelly, L. (2009). Different systems, similar outcomes? Tracking attrition in reported rape cases across Europe. London: CWASU.

Temkin, J., \& Krahe, B. (2008). Sexual Assault and the Justice Gap: A Question of Attitude. Oxford : Hart. von Hofer, H. (2000). Crime statistics as constructs: The case of Swedish rape statistics. European Journal on Criminal Policy and Research, 8(1), 77-89. 